\title{
MODELLING AND SIMULATION METHODOLOGY FOR DYNAMIC RESOURCES ASSIGNMENT SYSTEM IN CONTAINER TERMINAL
}

\author{
Bo Lu \\ Institute of E-Commerce and Modern Logistics, \\ Dalian University, Xuefu Str. 10, Dalian, China
}

\begin{abstract}
As the competition among international container terminals has become increasingly fierce, every port is striving to maintain the competitive edge and provide satisfactory services to port users. By virtue of information technology enhancement, many efforts to raise port competitiveness through an advanced operation system are actively being made, and judging from the viewpoint of investment effect, these efforts are more preferable than infrastructure expansion and additional equipment acquisition. Based on simulation, this study has tried to prove that RFID-based real-time location system (RTLS) data collection and dynamic operation of transfer equipment brings a positive effect on the productivity improvement and resource utilization enhancement. Moreover, this study on the demand for the real-time data for container terminal operation have been made, and operation processes have been redesigned along with the collection of related data, and based on them, simulations have been conducted. As a result of them, much higher productivity improvement could be expected.
\end{abstract}

Keywords: Container Terminal, Resources Assignment System, Modelling, Simulation

\section{INTRODUCTION}

As the competition among the world ports has become increasingly fierce, every port is striving to increase its investments constantly and lower its operational costs in order to maintain the competitive edge and provide satisfactory services to port users [1]. The unreasoning behavior, however, has induced that substantial waste and inefficiency exists in container port production [9].

Port markets used to be perceived as monopolistic due to the exclusive and immovable geographical location of the port and the unavoidable concentration of port traffic. However, the rapid development of international container and intermodal transportation has drastically changed the market structure from one of monopoly to one where fierce competition is prevalent in many parts of the world [11]. Many container ports no longer enjoy the freedom yielded by a monopoly over the handling of cargoes from their hinterland. Instead, they have to compete for cargo with their neighboring ports.

To maintain its competitiveness in such competitive condition, [7] claimed that container ports have to invest heavily in sophisticated equipments or in dredging channels to accommodate the most advanced and largest container ships in order to facilitate cost reductions for the container shipping industry [8].

It is important to note, however, that pure physical expansion is constrained by a limited supply of available land, especially for urban centre ports, and escalating 
environmental concerns [10]. In addition, the excessive and inappropriate investment also can induce the phenomenon of inefficiency and wasting of resources. In this context, improving the productive efficiency of container port appears to be the viable solution [2].

Realizing the facts, port authorities have shown great interest in efficient port management [12]. Thus, they are continually searching for strategies to meet growing demands by utilizing their resources reasonably [3].

In comparison with the pure physical expansion, more preferable efforts to raise port competitiveness through an advanced operation system are actively being made by virtue of information technology enhancement [5]. With respect to container terminal, the productivity of transfer equipment in the container yard has a significant effect upon the overall productivity [4]. [2] pointed out that the productivity maximization of transfer equipment, minimization of $\mathrm{C} / \mathrm{C}$ (container crane) and $\mathrm{T} / \mathrm{C}$ waiting time by effective fulfillment of work order, and remarkable utility rate improvement by dynamic vehicle assignment - all these are essential technologies for state-of-the-art port stevedoring system [13]. Therefore, the development of a dynamic assignment technique (or dynamic operation) based on a real-time location system is needed to increase the efficiency of transfer equipment [20].

Simulations have been widely applied into container terminal production [14]. Majority these terminal simulations are mainly aiming to forecast logistics volume, and to seek an optimal infrastructure and proper equipment combinations, so that they have been used at the planning stage of port construction [17]. The recent researches, however, have turned to develop a new simulator in order to advance an existing port operation system [21]. Therefore, this study utilizes the Arena as a simulation language, and utilizes a visual basic for a linkage to event handling and excel file [22]. In this study, the assignment problems of transfer equipment have been grouped into two ways: there are the existing batch and sequential method and a dynamic assignment method. After that, the simulations for both of them have been performed to measure their quantitative effect respectively [19]. Moreover, this study has divided a simulation model into a current one (As-Is) and a future (To-Be) model. For the purpose of improving the reliability of each simulation model, the current research has collected the operation data of Dalian International Container Terminal for a full year.

The paper is structured as follows: after the introductory section of Chapter 1 and the basic research of Chapter 2, there will be followed by the description of As-Is situation analysis and redesign To-Be model in Chapter 3. In so doing, the initial environment setup for simulation and the required definition of input/output variables have been described in Chapter 4. Simulation modeling of container terminals is derived in Chapter 5. Finally, conclusions are drawn in Chapter 6. The definitions of terms in this study are as follows:

- $\quad$ RTLS: RFID based real-time locating system.

- YT pooling: joint assignment of yard tractors.
- Dynamic operation: optimal assignment of yard tractors based on real-time data.

\section{OPERATION SITUATION OF CONTAINER TERMINAL}

In an effort to make a survey of utilization of real-time data, to find out current operational problems, and to listen to the field experts' requirements for improvement, the researcher have visited major container terminals five times from October to December 2011. As the interviewees were composed of managers who have experiences of more than 10 years, they can tell us about the necessity of real-time data and also provide us with the necessary data for simulations. By fact-finding field survey, the researchers have found out the following operational problems and the requirement for advancement.

\section{OPERATIONAL PROBLEMS}

In most cases, the bottlenecks in the operational process are usually caused by transfer equipment rather than quay cranes or yard cranes.

In the case of one or two terminals, a pooling system or a dual cycle system has been adopted for the load balance of transfer equipment [23]. But because of inaccurate location recognition and scanty wireless communication infrastructure [24], they have ended up in failure.

In case of most domestic ports, the final job location of a crane can be checked by crane operator's input, consequently lowering the accuracy of input data, and in case of transfer equipment, it is almost impossible to conduct location tracking.

\section{REQUIREMENTS FOR IMPROVEMENT}

According to interview [18], equipment on transfer crane for a job completion notice and an automatic sensor for jobs to be done on yard tractor are needed. Tracking of yard tractors is conducive to the enhancement of operational efficiency from the aspect of situational assignment of transfer equipment. In order to show the evidence for effectiveness of dynamic planning, it is necessary to handle more than three berths in making simulation model rather than a small-scale container terminal.

\section{PROCESS ANALYSIS AND REDESIGN}

\section{AS-IS ANALYSIS}

In the development of a simulation model to test the efficacy of dynamic operation based on RTLS, first of all, this study need to analyze the As-Is business process and also need to design a To-Be business process. The As-Is Y/T (yard tractor) operation method is based on a team unit, that is, a certain number of $\mathrm{Y} / \mathrm{Ts}$ per $\mathrm{C} / \mathrm{C}$ (container crane), thus performing the job of loading and unloading for $\mathrm{C} / \mathrm{C}$. At this time each 


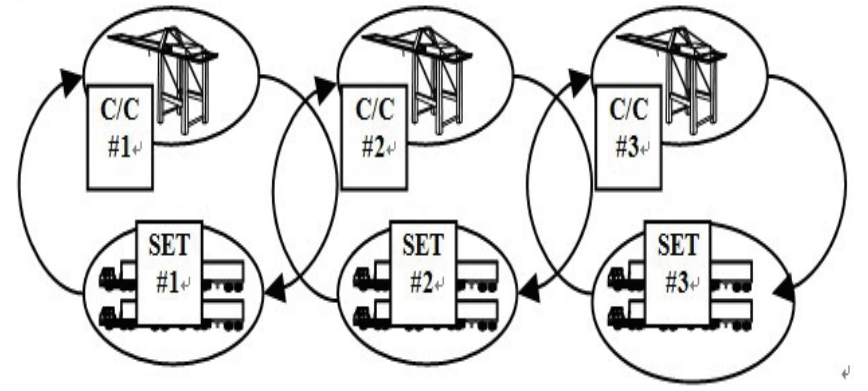

Fig.1 As-Is Y/T Operation Concept

In the sense that this batch and sequential operation of $\mathrm{Y} / \mathrm{T}$ for shipment on board the ship can be done orderly, it has a positive meaning, but it makes it impossible to exchange mutual cooperation with Y/Ts belonging to the other teams, consequently lowering job flexibility and availability of equipment [27-29].

\section{TO-BE MODEL}

Different from the above-mentioned batch and sequential operation of Y/T, a dynamic operation system doesn't have a job team composed of transfer equipment. Instead, Y/Ts freely support the job of several C/Cs. That is to say, Y/T pool can be composed for a ship or for a whole container terminal in figure 2.

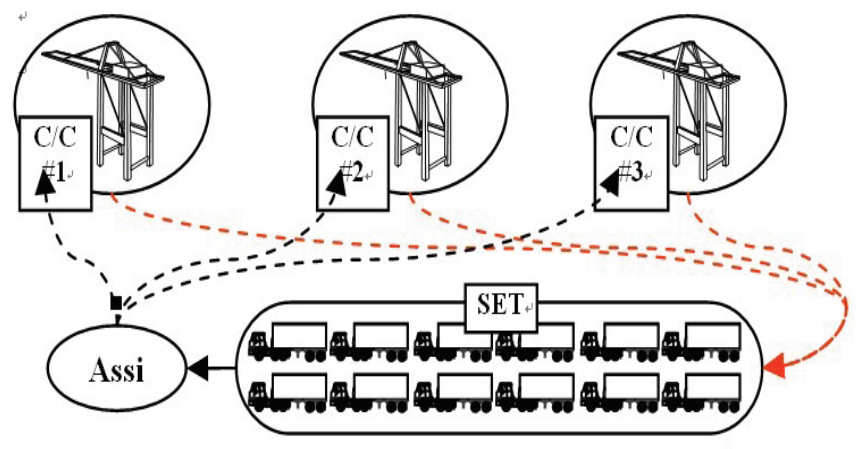

Fig.2 To-Be Y/T operation concept

As this method is FIFO-based assignment of transfer equipment, it can coordinate the imbalanced utility rate of transfer equipment. Also, considering the job situation including the moving distance from the current job place, $\mathrm{Y} / \mathrm{Ts}$ can be dynamically assigned to the $\mathrm{C} / \mathrm{C}$ and $\mathrm{T} / \mathrm{C}$, thus reducing empty movement considerably.

\section{INITIAL ENVIRONMENT SETUP FOR SIMULATION}

With regard to environment setup related to job situation, in case of a As-Is model, this study has assumed that one berth has three units of $\mathrm{C} / \mathrm{C}$, one $\mathrm{C} / \mathrm{C}$ has one team organization composed of five $\mathrm{Y} / \mathrm{Ts}$, and each team works for 10 hours. Running distance has been counted according to the required time of each movement line of Y/Ts (Figure 3). In case of the To-Be model, most conditions are similar to the As-Is model, but the only difference is that 15 units of $\mathrm{Y} / \mathrm{Ts}$ have dynamically been assigned to the three units of $\mathrm{C} / \mathrm{C}$.

\section{INPUT VARIABLES}

In order to produce an input data, the researchers have collected the data of the mother vessel for one year of 2011 at the Dalian International Container Terminal. The data includes: arrival and departure time per mother vessel, work time, number of assigned $\mathrm{Q} / \mathrm{C}$, number of $\mathrm{Y} / \mathrm{T}$, number of $\mathrm{T} / \mathrm{C}$, and storage position of the containers required to be carried. All the average values and probability distribution values have been calculated by input analysis of Arena.

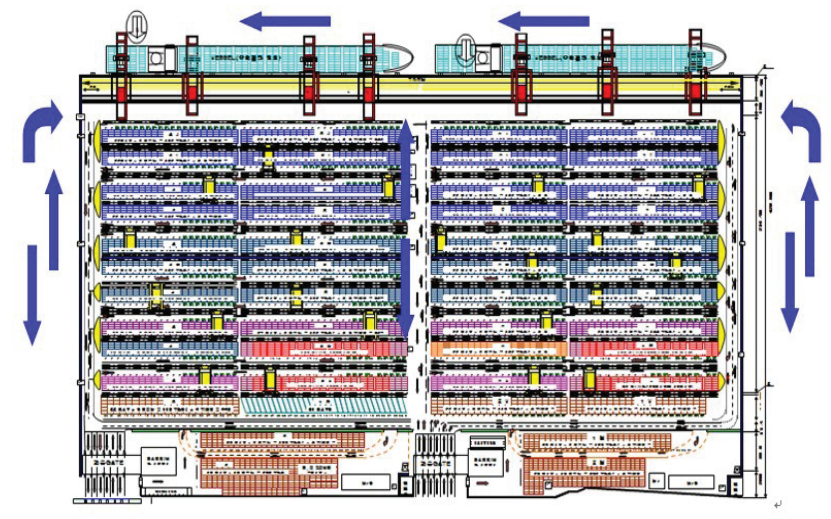

Fig.3 Movement line of $Y / T s$

In Table 1, the expression of 3 kinds probability distribution is shown that GAMM means gamma distribution, TRIA means triangular distribution and NORM means normal distribution.

Tab.1 Major simulation input variables

\begin{tabular}{|c|c|c|}
\hline Variable & Type & Value \\
\hline $\begin{array}{c}\text { Service time for } \\
\text { ships(from arrival to } \\
\text { departure) }\end{array}$ & Distribution & $\begin{array}{c}\text { 1+GAMM } \\
(2.58,5.48) \text { hrs }\end{array}$ \\
\hline Number of C/C & Average value & 3 units \\
\hline Loading time for C/C & Distribution & TRIA $(20,30,40) \mathrm{sec}$ \\
\hline Number of Y/T & Average value & 5 units/1GC \\
\hline Running speed of Y/T & Average value & 115 meters/min. \\
\hline Waiting time for T/C & Distribution & $\begin{array}{c}\text { TRIA }(0.4,1,1.5) \\
\text { min. }\end{array}$ \\
\hline T/C working hours & Distribution & NORM $(3,0.2)$ min. \\
\hline Y/T running distance & $\begin{array}{c}\text { Considering the terminal layout and } \\
\text { movement lines, they are converted into } \\
\text { meters. }\end{array}$ \\
\hline
\end{tabular}


Y/T's waiting time for T/C, working hours, Y/T's running speed and distance have been calculated according to the judgment of field experts. Table 1 and figure 4 show the values of major input variables.

\section{DEFINITIONS OF OUTPUT VARIABLES}

Output variables include: total handling volumes at the same hours, handling volumes per $\mathrm{Y} / \mathrm{T}$, and delayed working hours owing to Y/T's waiting.

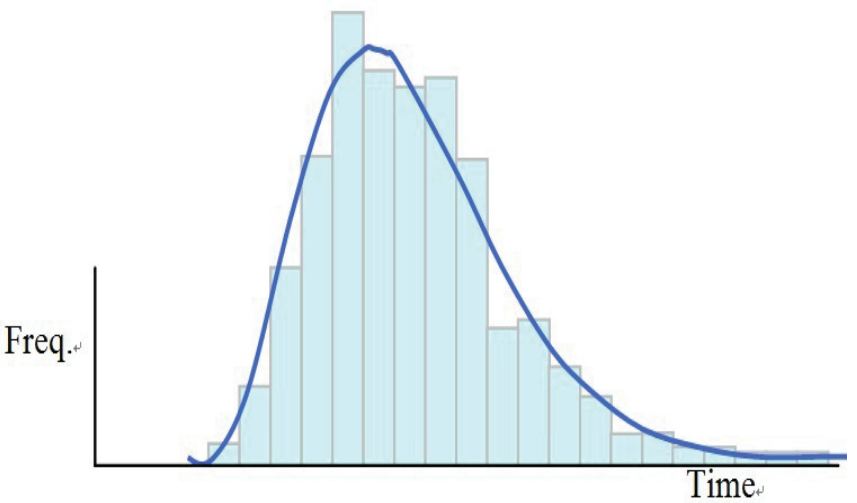

Fig. 4 Distribution of Service Time for Ship $(1+G A M M(2.58,5.48) h r s)$

And then the research on co-relationship between handling volumes and Y/T's working hour delay has been made.

\section{ANALYSIS RESULTS}

\section{INPUT VARIABLES}

Making the assumption that, this study has conducted modeling based on one ship. The modeling can be divided into three parts. First, if containers come, they needs to be checked whether there are available Y/T or not.

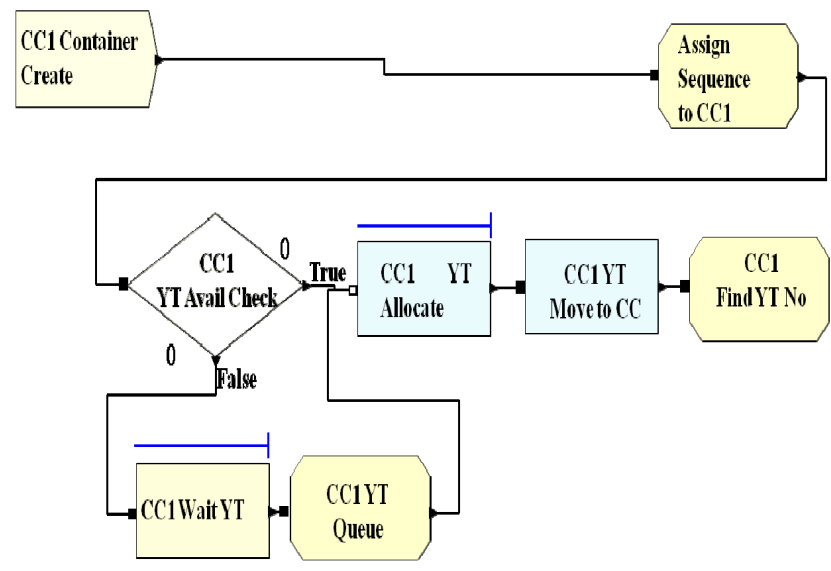

Fig.5 Available Y/T after job completion of C/C

If available, $\mathrm{Y} / \mathrm{Ts}$ will be assigned to $\mathrm{C} / \mathrm{C}$, and if not, $\mathrm{C} / \mathrm{C}$ is to wait $\mathrm{Y} / \mathrm{Ts}$. At this time, the $\mathrm{C} / \mathrm{C}$ 's waiting time for $\mathrm{Y} / \mathrm{T}$ is counted as shown in figure 5. $5 \mathrm{Y} / \mathrm{Ts}$ per team have been assigned by using the transporter module for $\mathrm{C} / \mathrm{C}$ of three units which have been summarized as table 2 .

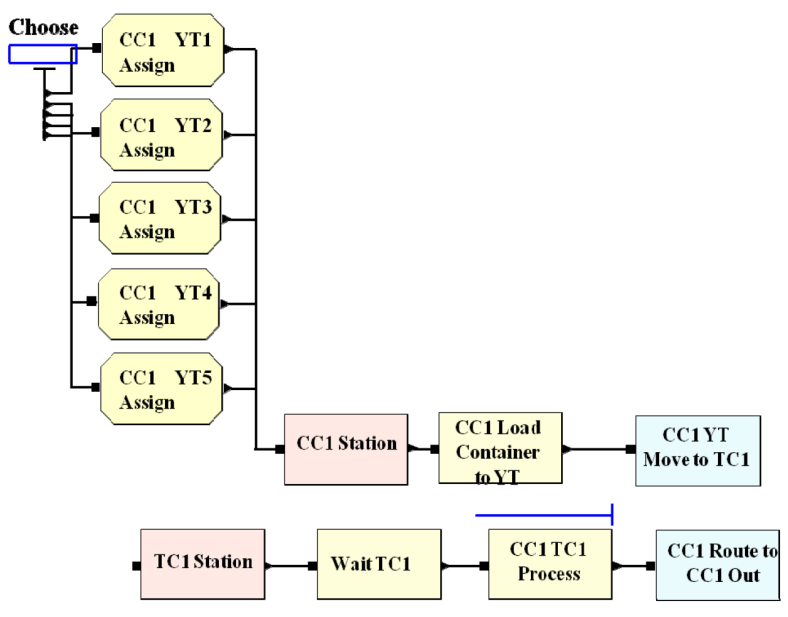

Fig. 6 Y/T moves to $\mathrm{T} / \mathrm{C}$

Secondly, if $\mathrm{Y} / \mathrm{Ts}$ are assigned, the corresponding containers will be loaded on the Y/Ts, and move to the T/Cs. At this time, the moving distance of $\mathrm{Y} / \mathrm{T}$ becomes the movement line's distance to the destination. If $\mathrm{T} / \mathrm{C}$ is under work, $\mathrm{Y} / \mathrm{T}$ has to wait as shown in figure 6. At this point, the moving distance of $\mathrm{Y} / \mathrm{T}$ is measured by a distance module which has been summarized as table 3 .

Tab.2 Transporter module

\begin{tabular}{|c|c|c|c|c|c|c|}
\hline \multicolumn{2}{|c|}{ Name } & Us & Type & Dis. Set & $\begin{array}{c}\text { V. } \\
(\mathrm{m} / \mathrm{h})\end{array}$ & $\begin{array}{c}\text { Initial } \\
\text { Position }\end{array}$ \\
\hline 1 & $\mathrm{CC} 1$ & 5 & $\begin{array}{l}\text { Free } \\
\text { Path }\end{array}$ & $\begin{array}{l}\mathrm{CC} 1 \mathrm{Y} / \mathrm{T} \\
\text { Distance }\end{array}$ & 10 & CC1 Station \\
\hline 2 & $\mathrm{CC} 2$ & 5 & $\begin{array}{l}\text { Free } \\
\text { Path }\end{array}$ & $\begin{array}{l}\mathrm{CC} 2 \mathrm{Y} / \mathrm{T} \\
\text { Distance }\end{array}$ & 10 & CC2 Station \\
\hline 3 & $\mathrm{CC} 3$ & 5 & $\begin{array}{l}\text { Free } \\
\text { Path }\end{array}$ & $\begin{array}{l}\text { CC3 Y/T } \\
\text { Distance }\end{array}$ & 10 & CC3 Station \\
\hline
\end{tabular}

Finally, if T/C's storage work is completion, Y/Ts will be released, and containers handling will also be ended as shown in Figure 7.

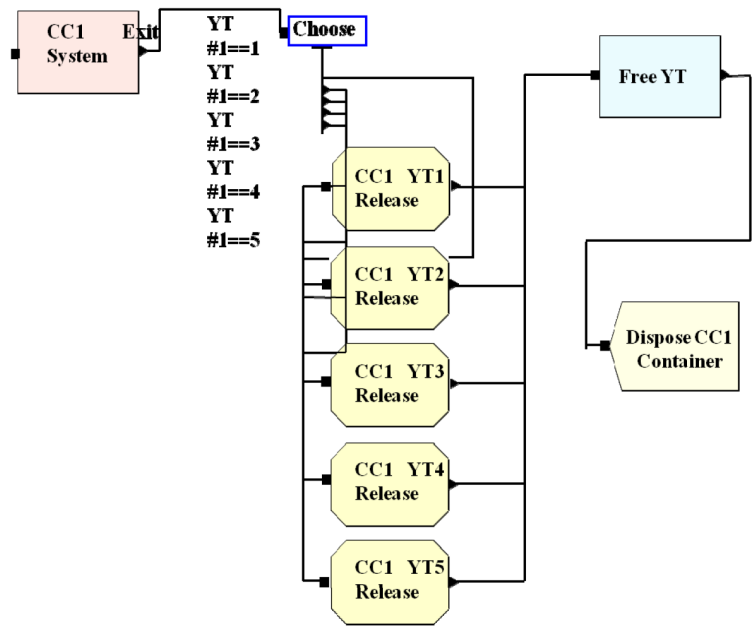

Fig.7 If T/C's storage work is completion, Y/T is released. 
If the above-mentioned modules are connected, the modeling for one berth is completed. And this modeling is used for the programming of the container terminal with three berths. A new (or To-Be) model is similar to the AsIs model, but the difference is that $\mathrm{Y} / \mathrm{T}$ is not assigned to a specific G/C (gantry crane) and also that if $\mathrm{Y} / \mathrm{Ts}$ are free, they are to be assigned to the nearest G/C. Figure 8 illustrates the difference between the two models.

Tab.3 Distance module

\begin{tabular}{|c|c|c|c|c|}
\hline No. & $\begin{array}{l}\text { Distance } \\
\text { Module } \\
\text { Name }\end{array}$ & $\begin{array}{l}\text { Beginning } \\
\text { Station }\end{array}$ & $\begin{array}{l}\text { Ending } \\
\text { Station }\end{array}$ & $\begin{array}{l}\text { Distance } \\
\text { (Meters) }\end{array}$ \\
\hline 1 & \multirow{2}{*}{$\begin{array}{c}\text { CC1 } \\
\text { Yard Tractor. } \\
\text { Distance }\end{array}$} & CC1 Station & TC1 & 378 \\
\hline 2 & & TC1 Station & CC1 Exit & 621 \\
\hline 3 & \multirow{2}{*}{$\begin{array}{c}\text { CC2 } \\
\text { Yard Tractor. } \\
\text { Distance }\end{array}$} & CC2 Station & $\begin{array}{c}\text { TC2 } \\
\text { Station }\end{array}$ & 351 \\
\hline 4 & & TC2 Station & CC2 Exit & 486 \\
\hline 5 & \multirow{2}{*}{$\begin{array}{c}\text { CC3 } \\
\text { Yard Tractor. } \\
\text { Distance }\end{array}$} & CC3 Station & $\begin{array}{c}\text { TC3 } \\
\text { Station } \\
\end{array}$ & 621 \\
\hline 6 & & TC3 Station & CC3 Exit & 297 \\
\hline
\end{tabular}

\section{TEST AND RESULTS}

In order to enhance the readability of simulation, animation has been made. Moreover, for helping understand the Y/T's flow, the animation has been depicted as shown in the figure 9.
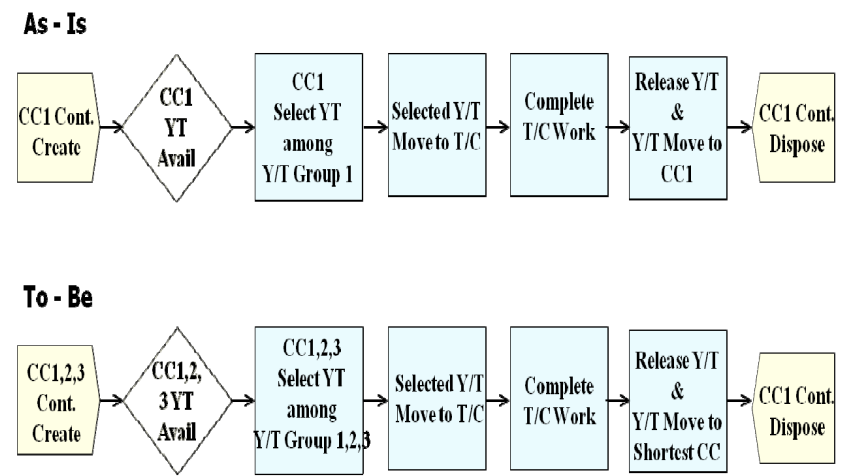

Fig.8 Difference between As-Is and To-Be model

Duplication tests have been made 100 times, and major output variables have been stored in the excel sheet by using VBA (visual basic for applications), and average values have been compared. In case of the As-Is model, it shows that 5 $\mathrm{Y} / \mathrm{Ts}$ are sequentially assigned to $\mathrm{C} / \mathrm{C}$ of one unit, and also shows the waiting queue of $\mathrm{Y} / \mathrm{Ts}$. In case of the new model, it illustrates that $15 \mathrm{Y} / \mathrm{Ts}$ for three $\mathrm{C} / \mathrm{C}$ are automatically assigned according to resources conditions and shortest distance.

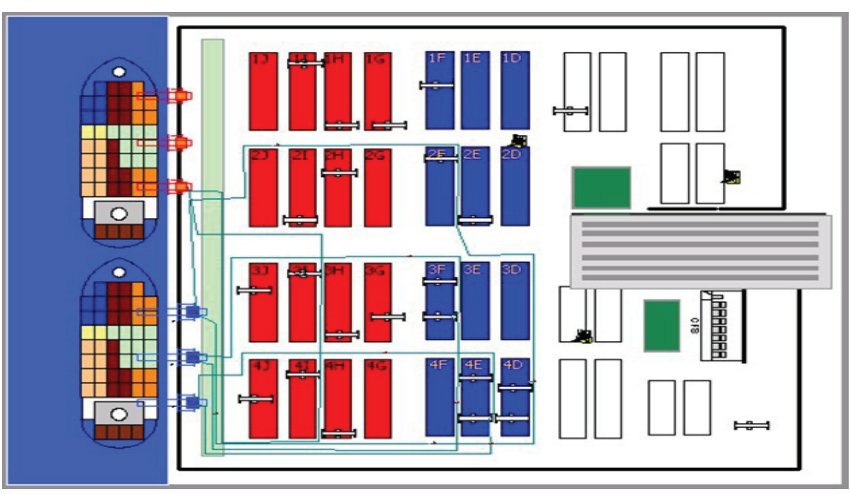

Fig.9 Simulation animation

As a result of this test, the major output values of both the As-Is model and the new model have been summarized as table 4 .

Tab.4 Major output values

\begin{tabular}{|c|c|c|c|}
\hline Output variables & Unit & $\begin{array}{c}\text { As-Is } \\
\text { model }\end{array}$ & To-Be model \\
\hline Total handling volume & TEU & 870 & 1,100 \\
\hline $\begin{array}{c}\text { Handling volume per Y/T } \\
\text { Avg. Delay Time of C/C in Y/T } \\
\text { waiting }\end{array}$ & Minutes & 1.6 & 0.8 \\
\hline
\end{tabular}

\section{CONCLUSIONS}

In the competitive circumstances, most ports were still committed to ongoing investment in the terminal facilities with a view to attracting more commercial vessels for anchorage. This produced an imbalance between inputs and outputs, which, in turn, produced an annual decline in operational efficiency. However, as [6] have claimed that 'Efficiency and productivity are core concepts of economics', and efficiency is also concerned with how to use limited resources more economically for any sort of production.

Moreover, by fact-finding field survey, the researchers have realized that the bottlenecks in the operational process are usually caused by transfer equipment rather than quay cranes or yard cranes. In the case of DITC, a pooling system or a dual cycle system has been adopted for the load balance of transfer equipment. Owing to inaccurate location recognition and scanty wireless communication infrastructure, however, they have ended up in failure. In addition, for most Chinese domestic ports, the final location of a crane can be checked by crane operator's input, consequently lowering the accuracy of input data, and in case of transfer equipment, it is almost impossible to conduct location tracking [25]. Therefore, transfer crane for an operation completion notice and an automatic sensor for operations to be done on yard tractor 
are necessary.

Tracking of yard tractors is conducive to the enhancement of operational efficiency from the aspect of situational assignment of transfer equipment.

As a benchmarking approach to research efficiency, the dynamic resources assignment of transfer equipment based on real-time locating data can increase productivity by more than $25 \%$ over the current batch and sequential assignment method. If an error range is reduced by using RFID technology, and also if RTLS is applied not only to the transfer equipment, but also to the yard cranes and containers, much higher productivity improvement could be expected. By doing this, the possible waste of resources and the industry best practice can be identified.

Nowadays, terminal operation systems of many advanced countries are becoming more intelligent and object-oriented, and also tremendous efforts are being made to actively and speedily respond to the rapidly changing environments [26]. Therefore, RTLS is becoming more and more the core technology under production condition in container terminal.

However, this study has a few limitations. As dynamic operation of transfer equipment have a positive effect on container unloading, simulation of this study has been confined to container unloading, and so pooling has also been limited to the ship alone. In this sense, it is not completely safe to say that this study has shown enough proof for the efficiency of a whole container terminal. Moreover, sensitivity analysis on output variables has not been made enough, thus being unable to suggest diverse alternatives. Therefore, more researches will be made in these fields in the future study.

\section{ACKNOWLEDGMENTS}

This work was supported by the National Natural Science Foundation of China (71573028); 2014 Liaoning BaiQianWan Talents Program(2014Q013); Liaoning SocialSciencePlanning Fund Plan (L14CJY041); Liaoning Provincial Education Department (WJQ2015004); Dalian science and technology project (2015D21ZC001;2014D11ZC117); Program for Liaoning Excellent Talents in University (WJQ2015004); Dalian Jinzhou Science and technology project (RXYJRXSK-2015-002); Liaoning educational scientific research management think tank project (ZK2015090).

\section{REFERENCES}

1. Adolf K Y, Ng F P, Athanasios A P 2013 Journal of Transport Geography 27(2), 46-55.

2. Albalate D, Bel G, Fageda X 2013 Ocean Coast Manage, 71(1), 163-169.

3. Bel G 2011 Business History 53(5), 688-705.

4. Bendall H B, Brooks M R 2011 Transport Logistics 3(4), 384-405.
5. Blokker E, Vreeburg J, Dijk J 2010 Journal of Water Resources Planning and Management 136(19), 19-26.

6. Castillo-Manzano J I, Asencio-Flores J P 2012 Transport Reviews 32(4), 519-537.

7. Cullinane, K P B, Song D W, Gray R 2007 Transportation Research A: Policy and Practice 36, 743-762.

8. Cullinane K, Wang T F, Song D W 2010 Transportation Research Part A 40, 354-374.

9. Cheon S H, David E, Song D W 2010 Transportation Research Part E 46, 546-561.

10. De Borger B, De Bruyne D 2011 Transport Economics and Policy 45(2), 247-275.

11. Ducruet C, Lee S W, Ng K Y A 2010 Maritime Policy and Management 37(1), 17-36.

12. Forsund F R, Sarafoglou N 2010 Journal of Productivity Analysis 17, 23-40.

13. Fu Y M, Stuart A 2012 Regional Science and Urban Economics 42(3), 473-484.

14. Fan L, William W, Bruce D 2012 Transportation Research Part E: Logistics and Transportation Review 48(6) 1121-1136.

15. Ingrid O, Susanne S 2010 Regional Science and Urban Economics 40, 538-549

16. Jaipuria S, Mahapatra S 2014 Expert Systems with Applications 41, 2395-2408.

17. LU B, Park N K 2010 Journal of Korean Navigation and Port Research 34(7) 595-601.

18. Notteboom T E, 2010 Journal of Transport Geography $\mathbf{1 8}$, 567-583.

19. Rodrigue J P, Debrie J, Fremont A, Gouvernal E, 2010 Journal of Transport Geography 18, 519-529.

20. Wei S, Song J, Khan N I 2012 Hydrological Process 26, 281-296.

21. Wen-Tai H, Wang P 2012 Regional Science and Urban Economics 42(6), 975-986.

22. Woxenius J, Bergqvist R 2011 Journal of Transport Geography, 19, 680-688.

23. William G, Szymczak I K, Edward T 2012 Journal of Aerosol Science 54(12), 59-76. 
24. Wilson W W, Dahl B, Taylor S 2011 Transport Economics and Policy 45(1), 129-154.

25. Xiao R, Su S L, Wang J Q, Zhang Z H, Jiang D W, Wu J P 2013 Applied Geography 39, 158-171.

26. Lee, J; Yoo, C; Lee, JL.2014. Journal of Coastal Research. 72, 81-84.

27. Yang Z, Gu X S, Liang X Y, Ling L C 2010 Materials and Design 31, 1042-1049.

28. Du, JQ; Du, SJ; Shen, SL; Yin, ZY. 2015. Polish Maritime Research. 22(1), 126-135.

29. Zhu Y H, Drake S, Lü H S, Xia J 2010 Water Resources Management 24, 1089-1105.

\section{CONTACT WITH THE AUTHOR}

Bo Lu

lubo@ucas.ac.cn

Institute of E-Commerce and Modern Logistics

Dalian University

Xuefu Str. 10, Dalian

CHINA 